\title{
Elucidation of Anchoring and Restructuring Steps during Synthesis of Silica-Supported Vanadium Oxide Catalysts
}

Alyssa M. Love, ${ }^{\mathrm{a}}$ Carlos A. Carrero, ${ }^{\mathrm{a}}$ Alessandro Chieregato, ${ }^{\mathrm{a}}$ Joseph T. Grant, ${ }^{\mathrm{a}}$ Sabrina Conrad, ${ }^{\mathrm{a}, \mathrm{c}}$ René Verel, ${ }^{\mathrm{c}}$ Ive Hermans, ${ }^{\mathrm{a}, \mathrm{b},{ }^{*}}$

a University of Wisconsin - Madison, Department of Chemistry, 1101 University Avenue, Madison WI 53706, USA

${ }^{\mathrm{b}}$ University of Wisconsin - Madison, Department of Chemical and Biological Engineering, 1415 Engineering Drive, Madison WI 53706, USA

${ }^{\mathrm{c}}$ ETH Zurich, Department of Chemistry and Applied Biosciences, Vladimir Prelog Weg 2, 8093 Zurich, Switzerland

*corresponding author. Email: hermans@chem.wisc.edu 


\section{$\underline{\text { Figures }}$}
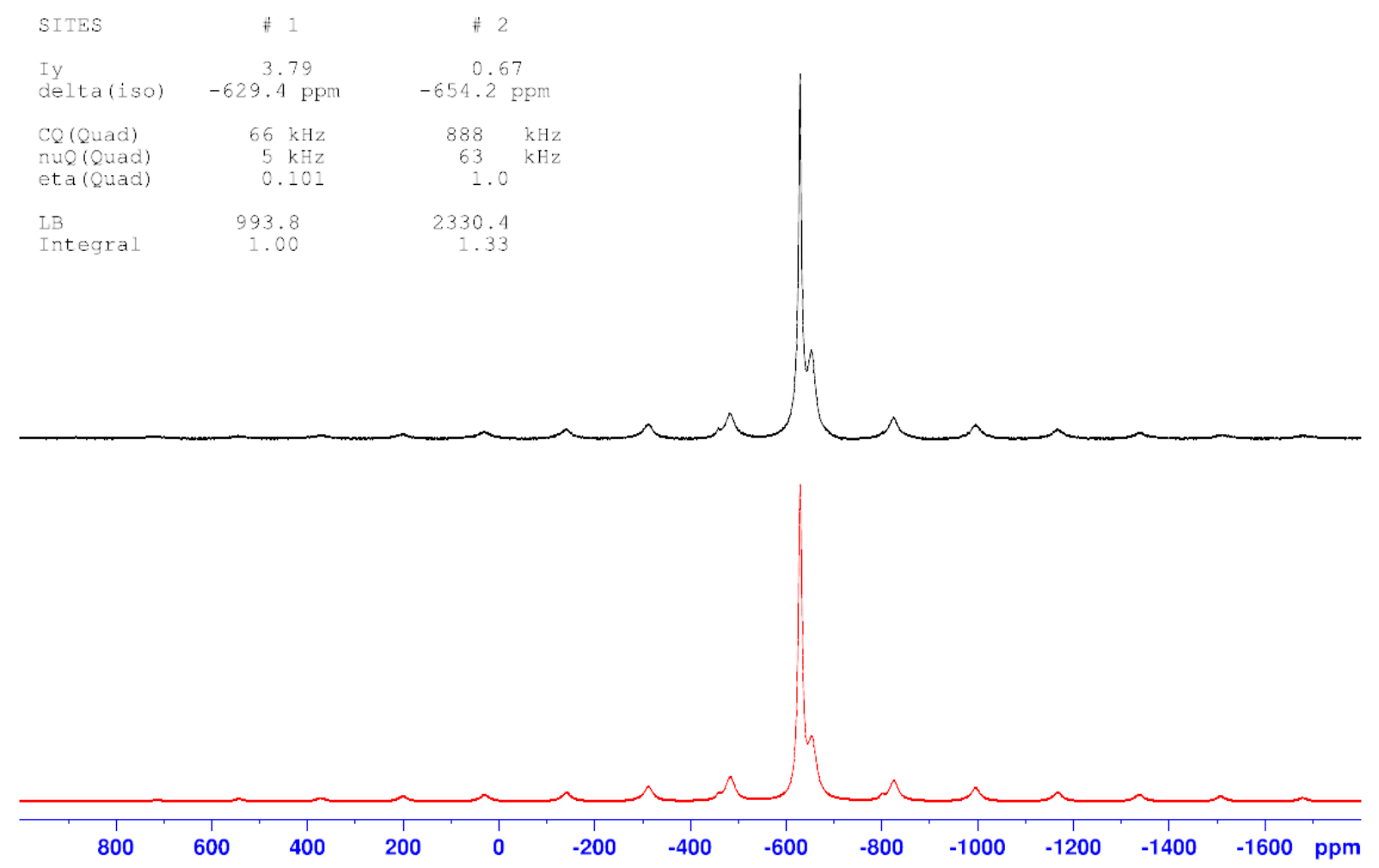

Figure S1. Comparison of experimental ${ }^{51} \mathrm{~V}$ MAS NMR spectrum of $\mathrm{V} / \mathrm{SiO}_{2(700)}$ (top, black trace) with simulated $\mathrm{V} / \mathrm{SiO}_{2(700)}{ }^{51} \mathrm{~V}$ MAS NMR spectrum (bottom, red trace). Similar fitting was also done for the pre-silylated V/TMS$\mathrm{SiO}_{2(700)}$ material; key fitting parameters are given in Table Si. 

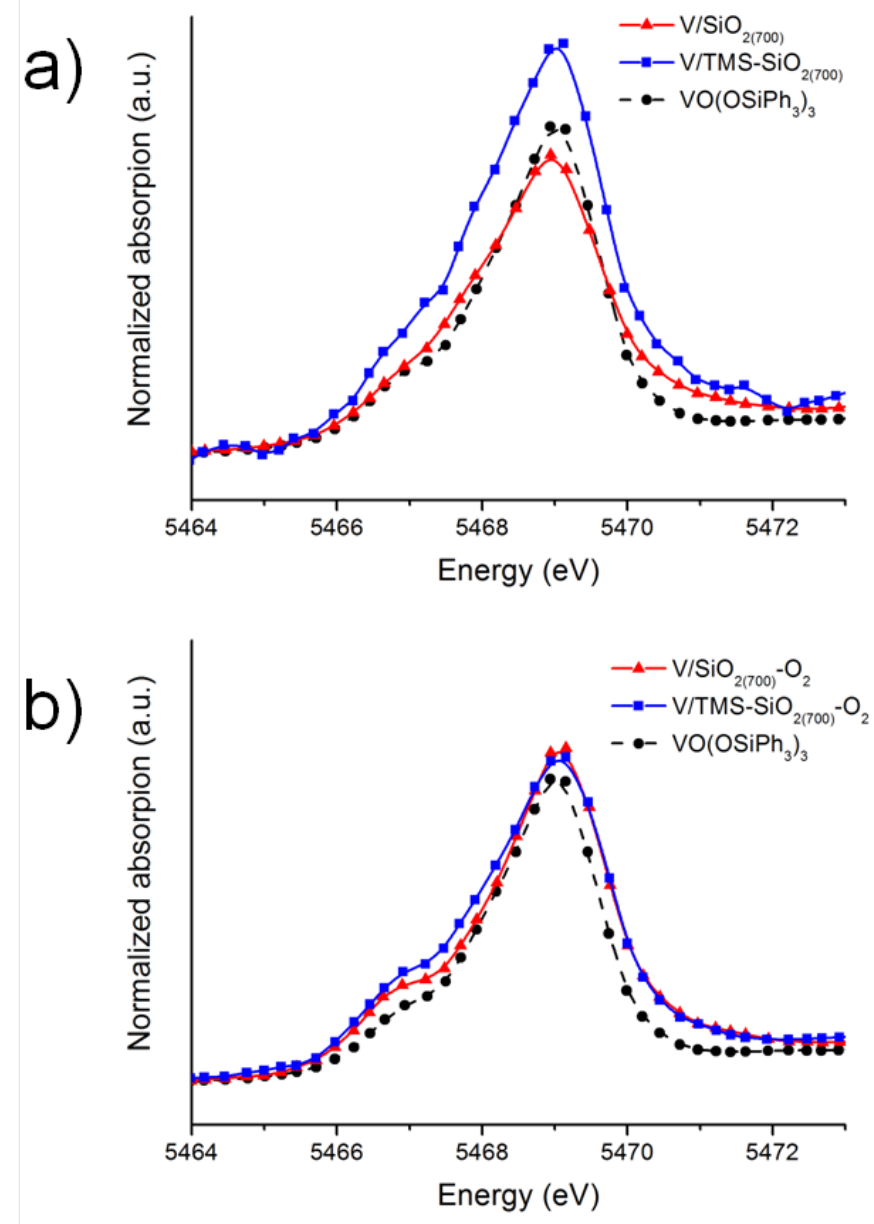

Figure S2. (a) Pre-edge peaks in the normalized vanadium K-edge XANES spectra for uncalcined supported vanadium

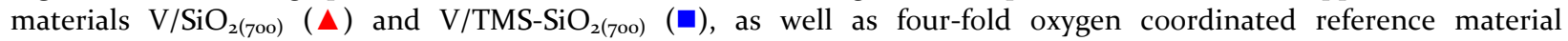
$\mathrm{VO}\left(\mathrm{OSiPh}_{3}\right)_{3}(\bullet)$ (b) pre-edge peaks in the normalized XANES spectra for calcined supported vanadium materials $\mathrm{V} / \mathrm{SiO}_{2(700)}-\mathrm{O}_{2}(\boldsymbol{\Delta})$ and $\mathrm{V} / \mathrm{TMS}-\mathrm{SiO}_{2(700)}-\mathrm{O}_{2}(\boldsymbol{\square})$, as well as four-fold oxygen coordinated reference material $\mathrm{VO}(\mathrm{OSiPh})_{3}$ $(\bullet)$. 

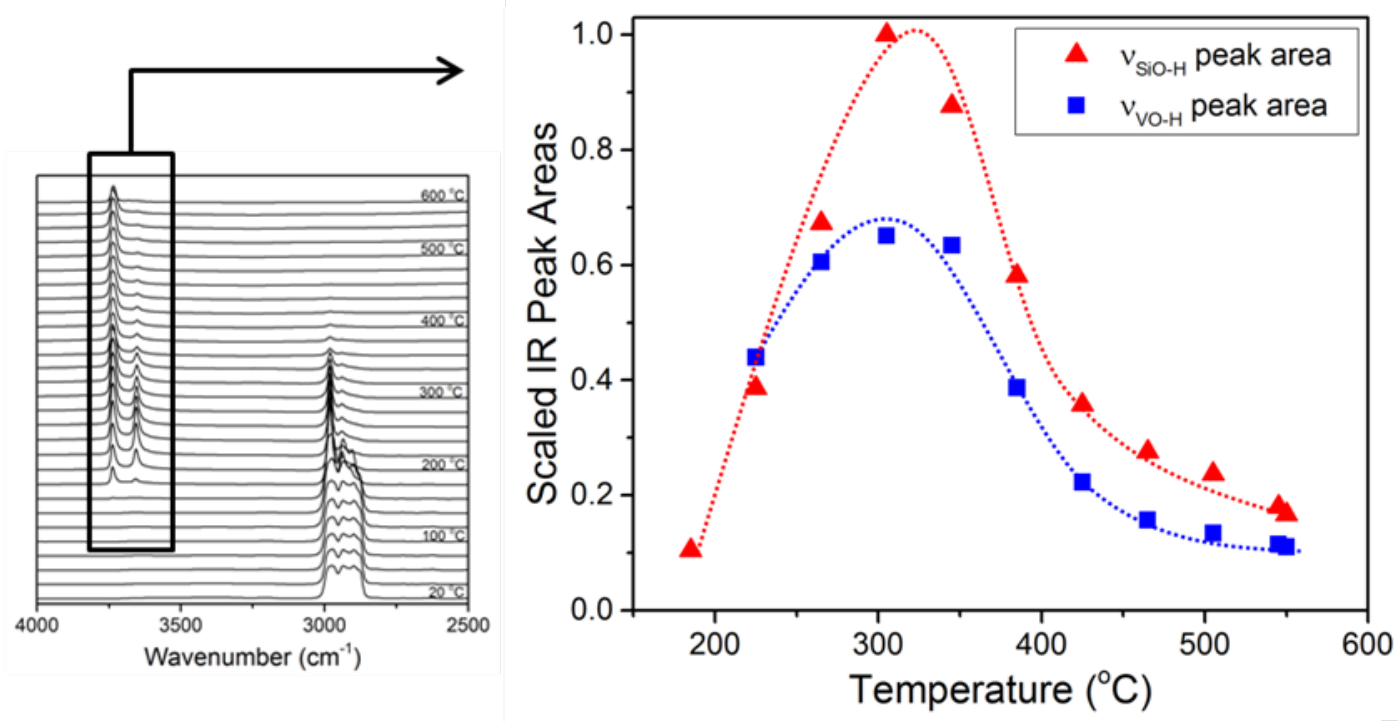

Figure S3. Peak areas for SiO-H ( $\mathbf{\Delta})$ and VO-H ( $\boldsymbol{\square})$ stretches observed in DRIFTS as a function of calcination temperature, pictured with dotted trendlines for each data set. While integration of DRIFTS spectra is not quantitative, they do give qualitative information about the abundance of these stretches as a function of calcination temperature.

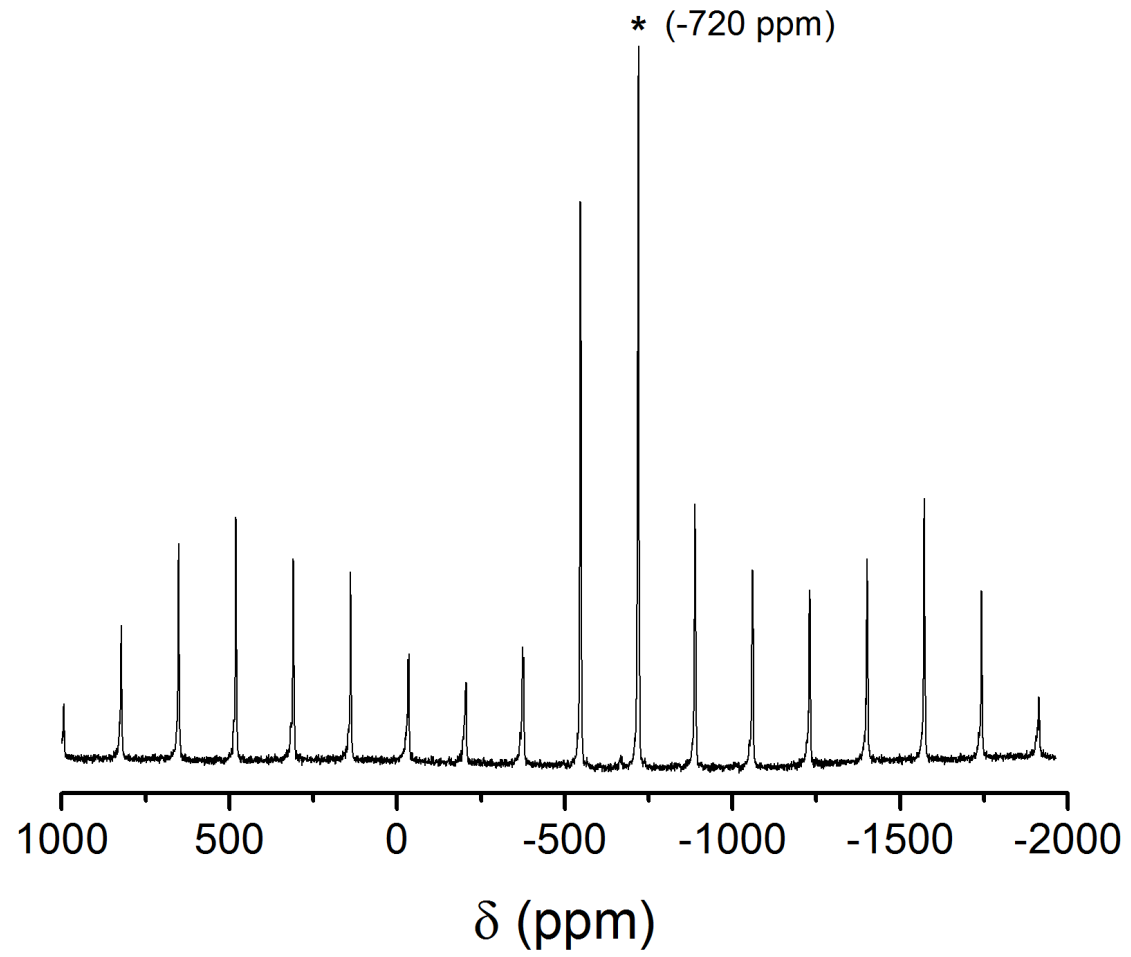

Figure $\mathbf{S}_{4} \cdot{ }^{51} \mathrm{~V}$ MAS NMR of model compound tris(triphenylsiloxy) vanadium oxide $\left(\mathrm{VO}\left(\mathrm{OSiPh}_{3}\right)_{3}\right)$. The isotropic shift is denoted by an asterisk $\left(^{*}\right)$. 


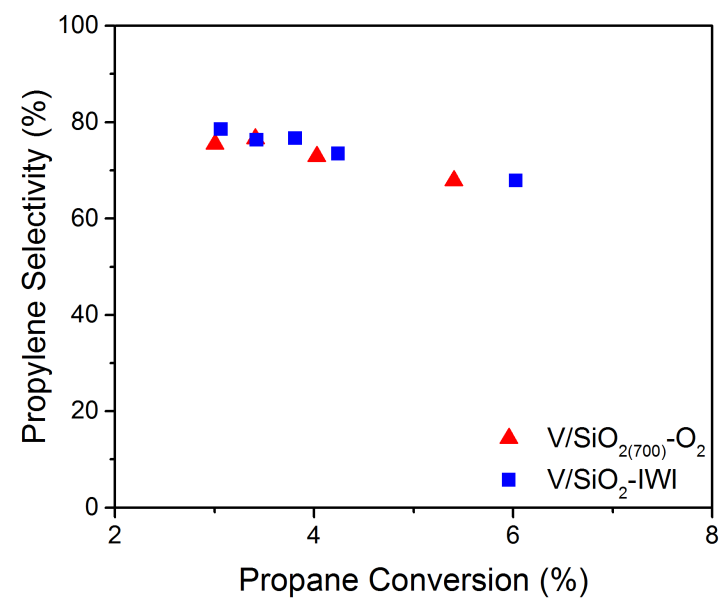

Figure S5. Propene selectivity versus propane conversion data for the oxidative dehydrogenation (ODH) of propane over dispersed vanadia on silica prepared by grafting $\left(\mathrm{V} / \mathrm{SiO}_{2(700)}-\mathrm{O}_{2}, \mathbf{\Delta}\right)$ and by incipient wetness impregnation $\left(\mathrm{V} / \mathrm{SiO}_{2-}\right.$ IWI, $\mathbf{\square})^{\text {a }}$

${ }^{\mathrm{a}}$ The material $\mathrm{V} / \mathrm{SiO}_{2}-\mathrm{IWI}$ was synthesized via incipient wetness impregnation. Prior to impregnation, silica (Aerosil $200^{\circledast}$ from Degussa, specific surface area of $200 \mathrm{~m}^{2} \cdot \mathrm{g}^{-1}$ ) was dried under static conditions overnight at $120{ }^{\circ} \mathrm{C}$. Impregnation was performed inside a glovebox under a dry $\mathrm{N}_{2}$ atmosphere. A solution of vanadium oxytriisopropoxide $\left(\mathrm{VO}\left(\mathrm{O}^{i} \mathrm{Pr}\right)_{3}\right.$; Sigma-Aldrich) in dry isopropanol (Sigma-Aldrich; 99.5\%) was prepared with such a ratio of $\mathrm{VO}\left(\mathrm{O}^{i} \mathrm{Pr}\right)_{3}$ to isopropanol so as to achieve a vanadium loading of ca. $3 \mathrm{wt}$ \% (comparable to the V-loading on the grafted sample), while using a total solution volume equal the pore volume of the support. This solution was then mixed with the silica support. The impregnated sample was vacuum-dried inside the glovebox and transferred to a calcination oven where it was dried under a flow of $\mathrm{N}_{2}$ at $120{ }^{\circ} \mathrm{C}$ for $3 \mathrm{~h}$, ramped to 550 ${ }^{\circ} \mathrm{C}$ at $1^{\circ} \mathrm{C} \cdot \mathrm{min}^{-1}$ under dry air, and calcined at $550{ }^{\circ} \mathrm{C}$ for $3 \mathrm{~h}$. 
$\underline{\text { Tables }}$

\begin{tabular}{|c|c|c|c|c|}
\hline \multirow{2}{*}{ Peak } & Material & Shift (ppm) & Linewidth (kHz) & $\begin{array}{c}\text { Quadrupolar Coupling } \\
\text { Constant (kHz) }\end{array}$ \\
\hline \multirow{2}{*}{ Peak 1 } & ${\mathrm{V} / \mathrm{SiO}_{2(700)}}^{*}$ & -629.4 & 0.9 & 66 \\
\cline { 2 - 5 } & $\mathrm{V} / \mathrm{TMS}-\mathrm{SiO}_{2(700)}$ & -631.3 & 1.3 & 79 \\
\hline \multirow{2}{*}{ Peak 2 } & $\mathrm{V} / \mathrm{SiO}_{2(700)}$ & -654.2 & 2.3 & 888 \\
\cline { 2 - 5 } & $\mathrm{V} / \mathrm{TMS}-\mathrm{SiO}_{2(700)}$ & $-657 \cdot 3$ & 3.0 & 866 \\
\hline
\end{tabular}

Table S1. Key parameters derived from ${ }^{51} \mathrm{~V}$ MAS NMR simulation of $\mathrm{V} / \mathrm{SiO}_{2(700)}$ and $\mathrm{V} / \mathrm{TMS}-\mathrm{SiO}_{2(700)}$.

\begin{tabular}{|c|c|c|c|}
\hline \multicolumn{2}{|c|}{ Material } & BET Surface Area* $\left.\mathbf{( m}^{2} / \mathbf{g}\right)$ & Vanadium loading* $($ wt \% V) \\
\hline \multirow{3}{*}{$\begin{array}{c}\text { Support } \\
\text { Materials }\end{array}$} & $\mathrm{SiO}_{2(700)}$ & $186 \pm 6$ & - \\
\cline { 2 - 4 } & $\mathrm{SiO}_{2(800)}$ & $193 \pm 6$ & - \\
\hline \multirow{3}{*}{$\begin{array}{c}\text { Vanadium } \\
\text { Grafted } \\
\text { Materials }\end{array}$} & $\mathrm{TMS}^{2} \mathrm{SiO}_{2(700)}$ & $191 \pm 5$ & $2.92 \pm 0.3$ \\
\cline { 2 - 4 } & $\mathrm{V} / \mathrm{SiO}_{2(700)}$ & - & $0.90 \pm 0.2$ \\
\cline { 2 - 4 } & $\mathrm{V} / \mathrm{TMS}-\mathrm{SiO}_{2(700)}$ & - & $2.89 \pm 0.3$ \\
\hline
\end{tabular}

Table S2. Summary of BET surface areas, ICP loadings for key supports/grafted materials described in main text. *Vanadium loading and BET surface area errors estimated based on three repetitions of each measurement (BET and ICP) for each material. 